\title{
Adherence to insulin treatment in insulin-naïve type 2 diabetic patients initiated on different insulin regimens
}

\section{Dilek Gogas Yavuz \\ Sevim Ozcan \\ Oguzhan Deyneli}

Department of Endocrinology and Metabolism, Marmara University School of Medicine, Istanbul, Turkey
Correspondence: Dilek Gogas Yavuz Department of Endocrinology and Metabolism, Marmara University School of Medicine, Fevzi Çakmak Mahallesi, Mimar Sinan Caddessi No:4I, Pendik Kaynarca Istanbul 34890, Turkey

$\mathrm{Tel}+902166254685$

Fax +90216625 4685

Email dilekyavuz2004@yahoo.com
This article was published in the following Dove Press journal:

Patient Preference and Adherence

25 August 2015

Number of times this article has been viewed

Objective: We aimed to evaluate adherence to insulin treatment in terms of treatment persistence and daily adherence to insulin injections among insulin-naïve type 2 diabetic patients initiating insulin therapy with basal (long acting), basal-bolus, and premixed insulin regimens in a tertiary endocrinology outpatient clinic.

Methods: A total of 433 (mean age of $55.5 \pm 13.0$ years; $52.4 \%$ females) insulin-naïve type 2 diabetic patients initiated on insulin therapy were included in this questionnaire-based phone interview survey at the sixth month of therapy. Via the telephone interview questions, patients were required to provide information about persistence to insulin treatment, self-reported blood glucose values, and side effects; data on demographics and diabetes characteristics were obtained from medical records.

Results: Self-reported treatment withdrawal occurred in $20.1 \%$ patients, while $20.3 \%$ patients were nonadherent to daily insulin. Negative beliefs about insulin therapy (24.1\%) and forgetting injections $(40.9 \%)$ were the most common reasons for treatment withdrawal and dose skipping, respectively. Younger age ( $49.5 \pm 15.0$ vs $56.4 \pm 12.0$ years $)(P=0.001)$ and shorter duration of diabetes $(4.8 \pm 4.3$ vs $8.8 \pm 6.3$ years $)(P=0.0008)$ and treatment duration $(5.2 \pm 2.4$ vs $10.7 \pm 2.4$ months $)$ $(P=0.0001)$ were noted, respectively, in discontinuers vs continuers. Basal bolus was the most commonly prescribed insulin regimen $(51.0 \%)$, while associated with higher likelihood of skipping a dose than regular use $(61.3 \%$ vs. $46.0 \%, P=0.04)$.

Conclusions: Persistence to insulin therapy was poorer than anticipated but appeared to be higher in patients with the basal bolus regimen. Negative perceptions about insulin therapy seemed to be the main cause for poor adherence in our cohort.

Keywords: type 2 diabetes, insulin treatment adherence, basal-bolus insulin regimen, premixed insulin regimen

\section{Introduction}

Insulin therapy is underutilized due to easily avoidable challenges to clinicians, patients, and the health care system in type 2 diabetes treatment. ${ }^{1}$

Initiation, adherence and persistence have been considered amongst the critical accomplishments in effective insulin therapy, which requires involvement of both patient and the health care provider. ${ }^{2}$ Accordingly, reluctance of physicians to initiate or intensify insulin therapy despite the recognition of the problem as well as poor adherence to insulin among patients, which ranges from $60 \%$ to $65 \%$, have been indicated to substantially limit the real-world clinical effectiveness of exogenous insulin therapy. ${ }^{3-6}$

Consequently, despite the proven efficacy, omission of insulin therapy and thereby, prolonged periods of poor glycemic control have remained a clinical care challenge in diabetes, closely linked to negative clinical outcomes, including increased severity 
and progression of macrovascular and microvascular complications..$^{7-10}$

The barriers towards insulin therapy have been associated with easily avoidable challenges related to clinicians, patients, and the health care system in diabetes management. Therefore efforts to overcome the stigmatization of insulin use and thus patient-related challenges gain importance in diabetes management, for better patient adherence and self-management. ${ }^{1,11}$

Data from the multinational Global Attitudes of Patients and Physicians in Insulin Therapy (GAPP) survey revealed that insulin omission/nonadherence was reported to be highest in Turkey, followed by the USA, People's Republic of China and Japan, and lowest in France, Germany, UK and Spain; ${ }^{8,12}$ however, no country-specific data are available in Turkey considering the adherence to insulin therapy and reasons for treatment withdrawal in insulin-naïve type 2 diabetes patients.

Therefore, the present single-center study was designed to evaluate adherence to insulin treatment in terms of treatment persistence and daily adherence to insulin injections among insulin-naïve type 2 diabetic patients initiating insulin therapy with basal (long acting), basal-bolus, and premixed insulin regimens. Secondary objectives were to determine risk factors for treatment withdrawal and daily insulin nonadherence.

\section{Methods}

\section{Study population}

Of 807 insulin-naïve type 2 diabetes patients initiated on insulin therapy at the Marmara University School of Medicine Endocrinology outpatient clinic between October 2010 and October 2011, 433 patients (mean \pm standard deviation [SD] age of $55.5 \pm 13.0$ years; $52.4 \%$ females) who were able to be phone-interviewed 6 months after the initiation of insulin treatment and who met the inclusion criteria of the study were included in this questionnaire-based, cross-sectional survey. All patients included in the study were initiated on insulin pen therapy and trained with a structured program by the same registered diabetes nurse educator. Patients with gestational diabetes, steroid dependent diabetes, and type-1 diabetes were excluded from the study.

Verbal informed consent was obtained from each subject following a detailed explanation of the objectives and protocol of the study which was conducted in accordance with the ethical principles stated in the Declaration of Helsinki and approved by Marmara University Faculty of Medicine's Ethics Committee.

\section{Data collection and study parameters}

A questionnaire was applied via phone interview and among continuers, included questions about: omission/nonadherence; self-reported blood glucose values (within the past month and, if present, within the past week); characteristics of ongoing insulin treatment (type, ie, basal bolus vs premixed vs basal insulin; and dosage) and self-injection (yes/no); problems related to injection administration (discomfort/ pain/itching at injection site) (yes/no); change in dosage (yes/no); skipped dose(s) for at least once a week (yes/no); the number of skipped doses and most commonly skipped dose (morning/noon/evening/night) within the last 3 months; longest duration of skipping; and finally, reasons for dose skipping (forgetting [yes/no], hypoglycemia [yes/no]), drug unavailability (yes/no), consideration of injection unnecessary (yes/no), inability to eat (yes/no), and adverse events, such as hypoglycemia and weight gain); among nonpersistent patients, the reasons for treatment discontinuation were recorded, including: hypoglycemic events (yes/no), normalization of blood glucose levels (yes/no); physician decision (yes/no); family influence (yes/no); workload/ workplace conditions (yes/no); weight gain (yes/no); challenges in drug procurement (yes/no); allergic side effects (yes/no); fear of injection/bleeding (yes/no); unwillingness to use without indication (yes/no); concern about becoming dependent on insulin (yes/no); and/or negative beliefs about insulin therapy (yes/no).

Data on patient demographics, literacy rate, duration of diabetes, diabetes education, first insulin regimen, and dosage and glycemic parameters were obtained from medical records. Mean values for fasting blood glucose and postprandial blood glucose were calculated based on self-reported measurements in the past week and/or past month, as were glycated hemoglobin $\left(\mathrm{HbA}_{1 \mathrm{c}}\right)$ values.

\section{Persistence and daily insulin adherence}

This study focused on evaluating persistence and daily insulin adherence. Persistence was evaluated during the 6 months and was defined as the time from therapy initiation to discontinuation. Daily adherence to insulin was defined as the extent to which a patient acts in accordance with the prescribed interval and dose of a dosing regimen. ${ }^{13}$

Based on these definitions, the discontinuation of treatment after beginning was considered to be the cutoff point for nonpersistence, while for daily insulin adherence, skipping of at least one injection in a week was considered as nonadherence to insulin injections.

\section{Statistical analysis}

Statistical analysis was made using computer software (GraphPad InStat 3.0; GraphPad Software, Inc., San Diego CA, USA). The chi-square test was used for the comparison 
of categorical data, while Student's $t$-test and analysis of variance (ANOVA) were used for the parametric variables. Data were expressed as mean $\pm \mathrm{SD}$, minimum-maximum, number and percent, where appropriate. $P<0.05$ was considered statistically significant.

\section{Results}

\section{Patient demographics and baseline characteristics}

The data collected from medical records on baseline demographic characteristics and glycemic parameters and type of prescribed insulin regimen are shown in Table 1.

Basal bolus was the most commonly prescribed insulin regimen, as reported in $51.0 \%$ of patients, followed by basal insulin (NPH, detemir, or glargine) in $26.0 \%$, and premixed regimen in $22.0 \%$.

\section{Persistence to insulin treatment}

Nonadherence to insulin therapy was noted in $44.3 \%(n=192)$ of patients, including all-cause treatment discontinuation $(24.0 \%[\mathrm{n}=104])$ and nonadherence to daily insulin $(20.3 \%$ $[\mathrm{n}=88])$. Treatment withdrawal occurred in $87(20.1 \%)$ patients, excluding deaths $(n=17)$, being mainly at patients' discretion (75.9\%) and due to negative beliefs (risk of dependency and weight gain) about insulin therapy (24.1\%). Nonpersistence was based on physician's decision in $13.7 \%$ of cases, while insulin-related adverse events (major hypoglycemia, allergic skin reaction, and leg edema) accounted for $8.0 \%(n=7)$ of treatment withdrawals (Table 2$)$.

Patients nonpersistent to insulin treatment were younger $(P=0.001)$ and had a shorter diabetes duration $(P=0.0008)$ compared with the persistent group. No difference was noted

Table I Baseline patient characteristics

\begin{tabular}{|c|c|}
\hline \multicolumn{2}{|l|}{ Demographics } \\
\hline Age (year) & $55.5 \pm 13.0$ \\
\hline \multicolumn{2}{|l|}{ Sex, n (\%) } \\
\hline Female & $227(52.4)$ \\
\hline Male & $206(47.6)$ \\
\hline Diabetes duration (years) & $8.7 \pm 6.6$ \\
\hline \multicolumn{2}{|l|}{ Glycemic parameters } \\
\hline Fasting blood glucose (mg/dL) & $150.0 \pm 62.0$ \\
\hline Postprandial blood glucose (mg/dL) & $195.0 \pm 77.0$ \\
\hline $\mathrm{HbA}_{\mathrm{Ic}}(\%)$ & $11.2 \pm 1.5$ \\
\hline \multicolumn{2}{|l|}{ Prescribed insulin regimen, $\mathrm{n}(\%)$} \\
\hline $\begin{array}{l}\text { Basal bolus (NPH, detemir, glargin regular, } \\
\text { lispro, glulisin or aspart) }\end{array}$ & $220(51.0)$ \\
\hline Basal insulin (NPH, detemir, or glargine) & II $2(26.0)$ \\
\hline Premixed $(30 / 70,50 / 50$ or $25 / 75)$ & $95(22.0)$ \\
\hline Short acting (Regular human, lispro, glulisine or aspart) & $6(1.0)$ \\
\hline
\end{tabular}

Note: Values are expressed as mean \pm SD unless otherwise specified. Abbreviations: $\mathrm{HbA}_{\mathrm{lc}}$, glycated hemoglobin; SD, standard deviation.
Table 2 Questionnaire data on insulin treatment related items

\begin{tabular}{|c|c|}
\hline \multicolumn{2}{|l|}{ Blood glucose monitoring $(n=250), n(\%)$} \\
\hline Self-monitoring via glucometer & $230(92.0)$ \\
\hline Monitoring at hospital & $20(8.0)$ \\
\hline \multicolumn{2}{|l|}{ Administration of insulin pen ( $n=329), n(\%)$} \\
\hline Self-injection & $257(78.1)$ \\
\hline By others & $72(21.9)$ \\
\hline \multicolumn{2}{|l|}{ Evaluation of injection procedure $(n=320), n(\%)$} \\
\hline Painless & $278(87.0)$ \\
\hline Causes itching at the injection site & $42(13.1)$ \\
\hline Nonadherence, $\mathrm{n}(\%)$ & $192(44.3)$ \\
\hline Nonpersistence ${ }^{\#}$ & $104(24.0)$ \\
\hline Daily insulin nonadherence & $88(20.3)$ \\
\hline \multicolumn{2}{|l|}{ All-cause treatment discontinuation, $\mathrm{n}(\%)$} \\
\hline Including deaths & $104(24.0)$ \\
\hline Excluding deaths & $87(20.1)$ \\
\hline \multicolumn{2}{|l|}{ Reasons for treatment discontinuation," $\mathrm{n}(\%)$} \\
\hline Patient-related & $66(75.9)$ \\
\hline $\begin{array}{l}\text { Negative beliefs (risk of dependency, weight gain) } \\
\text { about insulin therapy }\end{array}$ & $21(24.1)$ \\
\hline Preference of oral medication & $18(20.6)$ \\
\hline Normalization of blood glucose levels & $16(18.3)$ \\
\hline Fear of injection/bleeding & $5(5.7)$ \\
\hline Influence of family members and friends & $6(6.8)$ \\
\hline Physician-related & $12(13.7)$ \\
\hline Adverse events & $7(8.0)$ \\
\hline Major hypoglycemia & $2(2.3)$ \\
\hline Allergic skin reaction & $3(3.5)$ \\
\hline Leg edema & $2(2.3)$ \\
\hline Challenges in drug procurement & $2(2.2)$ \\
\hline \multicolumn{2}{|l|}{ Reasons for dose skipping ( $n=88), n(\%)$} \\
\hline Forgetting & $36(40.9)$ \\
\hline Hypoglycemia & $8(9.0)$ \\
\hline Normalization of blood glucose & $5(5.6)$ \\
\hline Drug unavailability & $8(9.0)$ \\
\hline Feeling good/consideration of injection unnecessary & $20(22.7)$ \\
\hline Workload & $7(7.9)$ \\
\hline Inability to eat & $4(4.5)$ \\
\hline
\end{tabular}

Note: "Based on treatment withdrawal in 87 patients after exclusion of 17 deaths.

between two groups in terms of sex, literacy rate, and $\mathrm{HbA}_{1 \mathrm{c}}$ values (Table 3).

No difference was noted between insulin regimens in persistent patients in terms of age, sex, and diabetes duration (Table 4).

The insulin dosage in persistent patients at baseline as well as after $10.7 \pm 2.4$ months was determined to be higher in basal bolus regimens as compared with premixed and basal insulin regimens $(P<0.0001)$, despite an increase in dosage of premixed and basal insulin regimens during follow-up (Table 4).

\section{Adherence to daily insulin}

Among persistent patients, patients who were adherent to daily insulin were determined to have lower values for daily insulin dose $(P=0.03)$ and self-measured postprandial blood 
Table 3 Characteristics of patients persistent or nonpersistent with insulin treatment

\begin{tabular}{|c|c|c|c|}
\hline & \multicolumn{2}{|l|}{ Insulin treatment } & \multirow[t]{2}{*}{$\overline{P \text {-value }}$} \\
\hline & Persistent patients $(n=329)$ & Nonpersistent patients $(n=104)$ & \\
\hline Age (year) & $56.4 \pm 12.0$ & $49.5 \pm 15.0$ & $0.00 I^{\dagger, *}$ \\
\hline $\operatorname{Sex}(F / M), n$ & $179 / 150$ & $48 / 56$ & $0.5^{\ddagger}$ \\
\hline Literacy, n (\%) & $197(60.0)$ & $60(58.0)$ & $0.4^{\ddagger}$ \\
\hline Diabetes duration (year) & $8.8 \pm 6.3$ & $4.8 \pm 4.3$ & $0.0008^{\dagger, *}$ \\
\hline $\mathrm{HbA}_{\mathrm{lc}}(\%)$ & $10.1 \pm 1.8$ & $10.4 \pm 2$ & $0.4^{\dagger}$ \\
\hline Treatment duration (months) & $10.7 \pm 2.4$ & $5.2 \pm 2.4$ & $0.0001 *$ \\
\hline
\end{tabular}

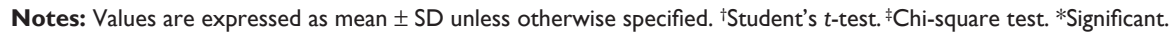

Abbreviations: $\mathrm{HbA}_{1 \mathrm{c}}$, glycated hemoglobin; $\mathrm{SD}$, standard deviation.

glucose levels ( $P=0.04)$ compared with nonadherent patients. A significant association was also noted between the type of insulin regimen and the overall likelihood of skipping a dose. Treatment adherence was better in terms of dose skipping in patients using premixed insulin and basal insulin as compared with basal bolus regimen $(P=0.04)$ (Table 5).

Nonadherence to daily insulin injections for consecutive days ( $2-5$ days) was noted in $9.4 \%$ of patients. Patients who skipped insulin injections for more than a day were reported to be on basal bolus (52.0\%), basal insulin (29.0\%), and premixed insulin (19.0\%) regimens. Participants reported forgetting both bolus and basal insulin doses and often felt uncertain about whether, when, and how much insulin they had taken. The major reasons for forgetting were disruptions to their daily routine, distraction by social events, minor interruptions, and "being busy".

Overall, 88 (20.3\%) patients skipped doses, with forgetting injections $(40.9 \%)$ and considering treatment unnecessary since feeling good $(22.7 \%)$ as the most commonly identified reasons (Table 2).

\section{Other clinical variables with respect to insulin regimens}

All patients were given a glucometer. Self-monitoring of blood glucose using the glucometer was reported by $92.0 \%$ of patients, while $8.0 \%$ preferred to have blood glucose measurements at hospital. Self-injection of insulin pen was identified by $78.1 \%$ of patients. Of 320 patients with data on evaluation of injection procedure, the injection was identified to be painless by $87.0 \%$, while considered to be associated with itching at the injection site by $13.1 \%$ of patients (Table 2).

The self-reported rate for minor hypoglycemia was significantly higher with the basal bolus regimen than with premixed and basal insulin regimens $(62.3 \%$ vs $54.1 \%$ and $50.0 \%$, respectively) $(P<0.05)$.

When considered according to insulin regimens, the number of follow-up visits attended by patients on a premixed insulin regimen (1.5 \pm 0.7$)$ was significantly lower than for those on basal bolus $(2.0 \pm 1.2)$ and basal $(2.1 \pm 0.2)$ insulin regimens $(P=0.03)$ (Table 4$)$.

\section{Discussion}

Our findings in a cohort of insulin-naïve type 2 diabetes patients initiated on insulin revealed poor persistence and adherence to insulin therapy. The basal bolus regimen was the most commonly initiated insulin regimen in our center and was associated with significantly higher dropout rates in the short term and the increased likelihood of skipping insulin injections

Table 4 Demographic and clinical variables in continuers according to insulin regimen

\begin{tabular}{|c|c|c|c|c|}
\hline & $\begin{array}{l}\text { Basal bolus } \\
(n=162)\end{array}$ & $\begin{array}{l}\text { Premixed } \\
(\mathrm{n}=\mathbf{8 5})\end{array}$ & $\begin{array}{l}\text { Basal insulin } \\
(n=78)\end{array}$ & $P$-value \\
\hline $\operatorname{Sex}(F / M), n$ & $87 / 75$ & $45 / 40$ & $47 / 31$ & $0.09^{\ddagger}$ \\
\hline Age (year) & $55.1 \pm 11.9$ & $56.0 \pm 10.5$ & $59.1 \pm 3.2$ & $0.059^{\dagger}$ \\
\hline Diabetes duration (year) & $8.4 \pm 6.3$ & $8.6 \pm 6.8$ & $8.2 \pm 6.0$ & $0.5^{\dagger}$ \\
\hline Daily insulin dose (IU/day) & $54.5 \pm 24.1$ & $39.3 \pm 18.0$ & $19.6 \pm 11.4$ & $<0.000 \mathrm{I}^{\dagger}$ \\
\hline Fasting blood glucose (mg/dL) & $153.5 \pm 66.6$ & $148.2 \pm 44.8$ & $|3| .4 \pm 49.0$ & $0.03^{\dagger}$ \\
\hline Postprandial blood glucose (mg/dL) & $181.0 \pm 73.0$ & $166.0 \pm 54.0$ & $197.0 \pm 74.0$ & $\mathrm{~ns}^{\dagger}$ \\
\hline Number of follow-up visits performed & $2.0 \pm 1.2$ & $1.5 \pm 0.7$ & $2.1 \pm 0.2$ & $0.03^{\dagger}$ \\
\hline Minor hypoglycemia, n (\%) & $101(62.3)$ & $46(54.1)$ & $39(50.0)$ & $<0.05^{\ddagger}$ \\
\hline Major hypoglycemia, n (\%) & $4(2.4)$ & $4(4.7)$ & $4(5.1)$ & $0.5^{\ddagger}$ \\
\hline
\end{tabular}

Notes: Values are expressed as mean \pm SD unless otherwise specified. ${ }^{\dagger} A N O V A .{ }^{\ddagger}$ Chi-square test.

Abbreviations: ANOVA, analysis of variance; SD, standard deviation. 
Table 5 Characteristics of the type 2 diabetic patients persistent with insulin therapy, in terms of skipping doses

\begin{tabular}{|c|c|c|c|}
\hline & \multicolumn{2}{|c|}{ Skipping doses } & \multirow[t]{2}{*}{$P$-value } \\
\hline & Yes $(n=88)$ & No $(n=24 I)$ & \\
\hline Age (years) & $54.0 \pm 10.5$ & $57.2 \pm 12.0$ & $0.03^{\dagger *} *$ \\
\hline Sex (F/M), n & $42 / 46$ & $139 / 102$ & $0.5^{\ddagger}$ \\
\hline Diabetes duration (year) & $7.6 \pm 5.5$ & $9.6 \pm 6.7$ & $0.07^{\dagger}$ \\
\hline Daily insulin dose (IU/day) & $46.9 \pm 24.0$ & $40.2 \pm 24.0$ & $0.03^{\dagger *} *$ \\
\hline \multicolumn{4}{|l|}{ Insulin regimen, $\mathrm{n}(\%)$} \\
\hline Basal bolus & $54(61.3)$ & III (46.0) & $0.04^{\ddagger} * *$ \\
\hline Premixed & $20(22.7)$ & $58(24.0)$ & \\
\hline Basal insulin & $14(15.9)$ & $72(27.3)$ & \\
\hline Fasting blood glucose (mg/dL) & $153.7 \pm 63.0$ & $146.5 \pm 57.0$ & $0.30^{\dagger}$ \\
\hline Postprandial blood glucose (mg/dL) & $191.5 \pm 65.0$ & $179.6 \pm 72.0$ & $0.04^{\dagger}, *$ \\
\hline Omitting dose for $>$ I day (2-5 days), $\mathrm{n}(\%)$ & $8(9.4)$ & - & - \\
\hline
\end{tabular}

Notes: Values are expressed as mean \pm SD unless otherwise specified. 'Student's $t$-test. ${ }^{*}$ Chi-square test. *Significant. Abbreviation: SD, standard deviation.

Insulin omission has been widely reported worldwide, varying from $19.9 \%$ in France to $42 \%$ in the United States and $44 \%$ in Japan. ${ }^{10,14}$ According to the multinational GAPP survey, insulin omission/nonadherence was reported to be highest in Turkey, followed by the USA, People's Republic of China, and Japan, and lowest in France, Germany, UK, and Spain.,12

Our findings are in line with a previous report of poor patient adherence in insulin therapy ${ }^{15}$ and in concordance with the data from past studies indicating one in three insulinnaïve patients who are prescribed insulin never become ongoing users. ${ }^{16}$ Our findings also coincide with previous study showing almost $60 \%$ of patients miss injections and $20 \%$ miss doses on a regular basis, ${ }^{17}$ and a level of $16 \%-49 \%$ persistence at 6-12 months. ${ }^{18,19}$

The basal bolus regimen was the most commonly prescribed insulin regimen in our cohort (51.0\%), which agrees with the consideration of this regimen to be typically used to maintain blood glucose control within the hospital setting, due to shorter onset and duration..$^{20,21}$ Notably, it was associated with significantly higher daily insulin dose, higher levels for fasting blood glucose, higher rate for minor hypoglycemia, and higher likelihood of skipping an insulin dose among continuers when compared with premixed and basal insulin regimens.

In fact, unlike our findings, basal bolus insulin therapy has been reported to minimize postprandial blood glucose excursions, maintain glycemic control, and to lead to the highest improvements in health-related quality of life, ${ }^{22}$ along with significant reductions in proportion of patients with $\mathrm{HbA}_{1 \mathrm{c}} \geq 9 \%$. $^{23}$ However, given the diverse duration of diabetes in our cohort, it should be noted that the superiority of a basal bolus regimen has been documented in selected patients with long-standing disease, poorly controlled with other antidiabetic drugs, and unstable profile. ${ }^{24-26}$
Use of the insulin pen has been associated with lower rates of hypoglycemia, greater adherence and persistence, and thereby, greater glycemic control. ${ }^{1}$ Accordingly, while all patients were on insulin pen therapy, identification of nonadherence in more than half of our cohort of diabetics emphasizes the need for further investigation of the determinants of high nonadherence to insulin therapy among Turkish diabetic patients; this is especially important given the likelihood of increased severity and progression of macrovascular and microvascular complications in cases of omission/nonadherence of insulin therapy. ${ }^{7,9,10}$

Factors related to injection, complexity of the regimen, and more frequent and inflexible dosing schedules have been considered to be the key treatment-related barriers to insulin therapy. ${ }^{5,19,27,28}$ Although, most (75.9\%) of the treatment withdrawals in our cohort occurred at the patient's discretion, the reasons identified for withdrawal involved negative beliefs about insulin therapy rather than fears related to injection or complexity and/or inflexibility of the dosing schedules. This seems to support the statement that use of insulin pens may overcome some of the patient-related challenges, including stigma and fear of initiating insulin therapy. 1,29,30

Also, the identification of insulin pen injection as a painless procedure by $87.0 \%$ of our patients is in line with the statements that fear of pain ranked fairly low among diabetic patients ${ }^{31}$ and that physicians often overestimate the patient's fear of injection pain leading to a preemptive decision to delay or withhold insulin. ${ }^{1}$

Although all patients in our cohort had structured education on insulin treatment, negative beliefs about insulin treatment rather than its complexity and inflexibility were noted as the main determinants of treatment withdrawal among discontinuers. This suggests that inquiring about and actively listening to 
patients' beliefs, concerns, and/or fear about insulin therapy may offer clinicians the opportunity to appropriately address the patients who will be reluctant to initiate insulin, as well as any preexisting misconceptions. ${ }^{32-34}$ Of note, it has been stated that it is less likely that patients choose to be nonadherent and more likely that they struggle with the constraints placed by diabetes on their lifestyle. ${ }^{35}$ Accordingly, increased awareness of patients about the progressive nature of type 2 diabetes with the eventual need of insulin therapy is as likely as enhanced flexibility of insulin therapy to enable better patient adherence and improved patient outcomes. ${ }^{1,34-36}$

Lack of consensus among national guidelines and recommendations has been considered to be likely to induce the clinical inertia observed among clinicians. ${ }^{37-39}$ Hence, given that more than two-thirds of continuers in our cohort had attended regular follow-up visits and that treatment discontinuation was based on a physician decision in $13.7 \%$ of discontinuers, the role of physician-related factors in insulin adherence should also be emphasized.

Certain limitations to this study should be considered. First, the relatively small sample size and single-center design limits the generalization of our findings to the overall diabetic population. Second, our findings are based on crosssectional data on self-reported medication adherence, which could have been biased by patients' foreknowledge of their laboratory results. Third, lack of data on adherence to the other aspects of diabetes, such as diet and physical activity, is another possible limitation, which otherwise would extend the knowledge obtained in the current study. Additionally, no data are available on diabetic complications, the lack of which may also interfere with nonadherence. Nevertheless, despite these certain limitations, given the paucity of the solid information on the subject, our findings represent a valuable contribution to the literature.

In conclusion, our findings in a cohort of insulin-naïve type 2 diabetes patients revealed nonadherence to insulin therapy in almost half of the study population, with treatment discontinuation and skipping an insulin dose in one-fifth of the study population. Younger aged patients with shorter duration of both diabetes and antidiabetic treatment were more likely to be discontinuers, while the basal bolus regimen was associated with poorer persistence and adherence to daily insulin injections. Our findings emphasize the role of negative beliefs about insulin treatment, rather than its complexity and inflexibility, in the decision to withdraw from treatment among discontinuers. Therefore, inquiring about and active listening to patients' beliefs, concerns, and/or fears regarding insulin therapy seem crucial in achieving better adherence and, thus, improved glycemic control in insulin initiators. This preliminary study provides evidence needed for further studies on patients' attitudes and beliefs about insulin treatment.

\section{Disclosure}

The authors report no conflicts of interest in this work.

\section{References}

1. Sorli C, Heile MK. Identifying and meeting the challenges of insulin therapy in type 2 diabetes. $J$ Multidiscip Healthc. 2014;7:267-282.

2. Peyrot M, Rubin RR. Perceived medication benefits and their association with interest in using inhaled insulin in type 2 diabetes: a model of patients' cognitive framework. Patient Prefer Adherence. 2011;5: 255-265.

3. Phillips LS, Branch WT, Cook CB, et al. Clinical inertia. Ann Intern Med. 2001;135(9):825-834.

4. Buysman E, Conner C, Aagren M, Bouchard J, Liu F. Adherence and persistence to a regimen of basal insulin in a pre-filled pen compared to vial/syringe in insulin-naïve patients with type 2 diabetes. Curr Med Res Opin. 2011;27(9):1709-1717.

5. Cramer JA. A systematic review of adherence with medications for diabetes. Diabetes Care. 2004;27(5):1218-1224.

6. Cheen HH, Lim SH, Huang MC, Bee YM, Wee HL. Adherence to premixed insulin in a prefilled pen compared with a vial/syringe in people with diabetes in Singapore. Clin Ther. 2014;36(7):1043-1053.

7. Del Prato S, Penno G, Miccoli R. Changing the treatment paradigm for type 2 diabetes. Diabetes Care. 2009;32 Supp1 2:S217-S222.

8. Peyrot M, Barnett AH, Meneghini LF, Schumm-Draeger PM. Insulin adherence behaviours and barriers in the multinational Global Attitudes of Patients and Physicians in Insulin Therapy study. Diabet Med. 2012; 29(5):682-689.

9. Morris AD, Boyle DI, McMahon AD, Greene SA, MacDonald TM, Newton RW; DARTS/MEMO Collaboration. Adherence to insulin treatment, glycaemic control, and ketoacidosis in insulin-dependent diabetes mellitus. Lancet. 1997;350(9090):1505-1510.

10. Aronson R. The role of comfort and discomfort in insulin therapy. Diabetes Technol Ther. 2012;14(8):741-747.

11. Wright A, Burden AC, Paisey RB, Cull CA, Holman RR; U.K. Prospective Diabetes Study Group. Sulfonylurea inadequacy: efficacy of addition of insulin over 6 years in patients with type 2 diabetes in the U.K. Prospective Diabetes Study (UKPDS 57). Diabetes Care. 2002;25(2):330-336.

12. pharmafile. com [homepage on the Internet]. Treatment flexibility will improve adherence in diabetes, study suggests. Samedan Ltd; 2011. Available from: http://www.pharmafile.com/news/161079/treatmentflexibility-will-improve-adherence-diabetes-study-suggests. Accessed July 2, 2015.

13. Peterson AM, Nau DP, Cramer JA, Benner J, Gwadry-Sridhar F, Nichol M. A checklist for medication compliance and persistence studies using retrospective databases. Value Health. 2007;10(1):3-12.

14. Peyrot M, Barnett AH, Meneghini LF, Schumm-Draeger PM. Factors associated with injection omission/non-adherence in the Global Attitudes of Patients and Physicians in Insulin Therapy study. Diabetes Obes Metab. 2012;14:1081-1087.

15. Spann SJ, Nutting PA, Galliher JM, et al. Management of type 2 diabetes in the primary care setting: a practice-based research network study. Ann Fam Med. 2006;4(1):23-31.

16. Karter AJ, Subramanian U, Saha C, et al. Barriers to insulin initiation: the translating research into action for diabetes insulin starts project. Diabetes Care. 2010;33(4):733-735.

17. Peyrot M, Rubin RR, Kruger DF, Travis LB. Correlates of insulin injection omission. Diabetes Care. 2010;33(2):240-245.

18. Dailey G, Kim MS, Lian JF. Patient compliance and persistence with antihyperglycemic drug regimens: evaluation of a medicaid patient population with type 2 diabetes mellitus. Clin Ther. 2001;23(8):1311-1320. 
19. Bonafede MM, Kalsekar A, Pawaskar M, et al. A retrospective database analysis of insulin use patterns in insulin-naïve patients with type 2 diabetes initiating basal insulin or mixtures. Patient Prefer Adherence. 2010;4:147-156

20. Knecht LA, Gauthier SM, Castro JC, et al. Diabetes care in the hospital: is there clinical inertia? J Hosp Med. 2006;1(3):151-160.

21. Schnipper JL, Barsky EE, Shaykevich S, Fitzmaurice G, Pendergrass ML. Inpatient management of diabetes and hyperglycemia among general medicine patients at a large teaching hospital. J Hosp Med. 2006;1(3): $145-150$.

22. Ratner R, Wynne A, Nakhle S, Brusco O, Vlajnic A, Rendell M. Influence of preprandial vs postprandial insulin glulisine on weight and glycaemic control in patients initiating basal-bolus regimen for type 2 diabetes: a multicenter, randomized, parallel, open-label study (NCT00135096). Diabetes Obes Metab. 2011;13(12):1142-1148.

23. Vinagre I, Sánchez-Hernández J, Sánchez-Quesada JL, María MÁ, de Leiva A, Pérez A. Switching to basal-bolus insulin therapy is effective and safe in long-term type 2 diabetes patients inadequately controlled with other insulin regimens. Endocrinol Nutr. 2013;60(5):249-253.

24. Fritsche A, Larbig M, Owens D, Häring HU; GINGER study group. Comparison between a basal-bolus and a premixed insulin regimen in individuals with type 2 diabetes-results of the GINGER study. Diabetes Obes Metab. 2010;12(2):115-123.

25. Liebl A, Prager R, Binz K, Kaiser M, Bergenstal R, Gallwitz B; PREFER Study Group. Comparison of insulin analogue regimens in people with type 2 diabetes mellitus in the PREFER Study: a randomized controlled trial. Diabetes Obes Metab. 2009;11(1):45-52.

26. Rosenstock J, Ahmann AJ, Colon G, Scism-Bacon J, Jiang H, Martin S. Advancing insulin therapy in type 2 diabetes previously treated with glargine plus oral agents: prandial premixed (insulin lispro protamine suspension/lispro) versus basal/bolus (glargine/lispro) therapy. Diabetes Care. 2008;31(1):20-25.

27. Oliveria SA, Menditto LA, Ulcickas Yood M, Koo YH, Wells KE, McCarthy BD. Barriers to the initiation of, and persistence with, insulin therapy. Curr Med Res Opin. 2007;23(12):3105-3112.

28. Odegard PS, Capoccia K. Medication taking and diabetes: a systematic review of the literature. Diabetes Educ. 2007;33(6):1014-1029; discussion 1030-1031.
29. Korytkowski M, Bell D, Jacobsen C, Suwannasari R; FlexPen Study Team. A multicenter, randomized, open-label, comparative, two-period crossover trial of preference, efficacy, and safety profiles of a prefilled, disposable pen and conventional vial/syringe for insulin injection in patients with type 1 or 2 diabetes mellitus. Clin Ther. 2003;25(11):2836-2848.

30. Flood T. Advances in insulin delivery systems and devices: beyond the vial and syringe. Insulin. 2006;1(3):99-108.

31. Nakar S, Yitzhaki G, Rosenberg R, Vinker S. Transition to insulin in Type 2 diabetes: family physicians' misconception of patients' fears contributes to existing barriers. J Diabetes Complications. 2007;21(4):220-226.

32. Polonsky WH, Hajos TR, Dain MP, Snoek FJ. Are patients with type 2 diabetes reluctant to start insulin therapy? An examination of the scope and underpinnings of psychological insulin resistance in a large, international population. Curr Med Res Opin. 2011;27(6):1169-1174.

33. Hayes RP, Fitzgerald JT, Jacober SJ. Primary care physician beliefs about insulin initiation in patients with type 2 diabetes. Int J Clin Pract. 2008;62(6):860-868.

34. Benroubi M. Fear, guilt feelings and misconceptions: barriers to effective insulin treatment in type 2 diabetes. Diabetes Res Clin Pract. 2011 93 Suppl 1:S97-S99.

35. Petznick AM. Identifying and addressing barriers to insulin acceptance and adherence in patients with type 2 diabetes mellitus. J Am Osteopath Assoc. 2013;113(4 Suppl 2):S6-S16.

36. Turner RC, Cull CA, Frighi V, Holman RR. Glycemic control with diet, sulfonylurea, metformin, or insulin in patients with type 2 diabetes mellitus: progressive requirement for multiple therapies (UKPDS 49). UK Prospective Diabetes Study (UKPDS) Group. JAMA. 1999;281(21): 2005-2012.

37. American Diabetes Association. Standards of medical care in diabetes 2014. Diabetes Care. 2014;37 Suppl 1:S14-S80.

38. Rodbard HW, Jellinger PS, Davidson JA, et al. Statement by an American Association of Clinical Endocrinologists/American College of Endocrinology consensus panel on type 2 diabetes mellitus: an algorithm for glycemic control. Endocr Pract. 2009;15(6):540-559.

39. LaSalle JR. Empowering patients during insulin initiation: a real-world approach. J Am Osteopath Assoc. 2010;110(2):69-78.
Patient Preference and Adherence

\section{Publish your work in this journal}

Patient Preference and Adherence is an international, peer-reviewed, open access journal that focuses on the growing importance of patient preference and adherence throughout the therapeutic continuum. Patient satisfaction, acceptability, quality of life, compliance, persistence and their role in developing new therapeutic modalities and compounds to optimize

\section{Dovepress}

clinical outcomes for existing disease states are major areas of interest for the journal. This journal has been accepted for indexing on PubMed Central. The manuscript management system is completely online and includes a very quick and fair peer-review system, which is all easy to use. Visit http://www. dovepress.com/testimonials.php to read real quotes from published authors. 